\title{
Ultrasound-guided Percutaneous Microwave Ablation of Small Renal Masses: Short- and Mid-term Results, Safety, Effectiveness, and Prognostic Contributions
}

\author{
Serkan Arıbal, (1D Eyüp Kaya \\ University of Health Sciences Turkey, Prof. Dr. Cemil Taşçıoğlu City Hospital, Clinic of Radiology, İstanbul, Turkey
}

\section{Abstract}

Objective: This present study aimed to evaluate the short- and mid-term results and outcomes, efficacy, safety, and possible prognostic contributions of ultrasound (US)-guided percutaneous microwave ablation (MWA) treatment performed on small renal masses (SRM).

Methods: We retrospectively analyzed the patients who had undergone US-guided percutaneous MWA of SRM using both their patient files that contained all of the follow-up informations and all the radiological images on the local picture archiving and communication system between July 2016 and July 2019. Age and gender of the patients were recorded. The following data and parameters were also obtained: histopathologic type of the SRM, pre and postablative tumor size in three dimensions (width, length, and height), tumor localization, the ablation procedure data (patient position, time, energy, presence of repeated ablation, adjacent structures, usage of protective techniques such as hydrodissection), time of local recurrence, and renal function test and parameters (urea, creatinine, and glomerular filtration rate).

Results: Thirteen patients with thirteen solitary SRMs that were ablated using MWA under USG-guidance were found. We performed one session for six lesions (46\%), two sessions for six lesions (46\%), and three sessions for one lesion (8\%). Mean ablation time for each session was 2.54 minutes (range: 1.5-4). We demonstrated a complete ablation, which is a primary success, in eleven patients (84\%) in the first month control computed tomography imaging. Two residual tumors were detected in two patients (16\%).

Conclusion: MWA for the treatment of SRM is an effective and safe method with high technical success and low complication rates and good short- and mid-term results and outcomes.

Keywords: Small renal mass, ultrasound, microwave ablation, minimal invasive, nephrectomy, percutaneous

\section{INTRODUCTION}

Regarding the current management of small renal masses (SRMs), which refers to tumors with sizes smaller than $4 \mathrm{~cm}$, there are several treatment methods depending on the patient's condition and clinical status, including open, laparoscopic or robotic partial or total nephrectomy, percutaneous or laparoscopic thermal and non-thermal ablations (1). Radical nephrectomy has been accepted for many years as the gold standard treatment approach in the management of renal tumors including SRM $(2,3)$. Due to the advances in surgical instruments and techniques, the fact that nephron-sparing surgery has similar functional and oncological outcomes in the treatment of renal tumors smaller than $4 \mathrm{~cm}$ (SRM) as radical nephrectomy has made this treatment approach to be accepted as the new gold standard in the treatment of SRMs (4-8).

While these developments were experienced in surgical treatment, a significant increase was observed in the incidental detection of these tumors in parallel with the technological developments in the field of radiological imaging (8). 
Moreover, with the advances in imaging methods that are used for the ablation guidance, minimally invasive local tumor treatments that began with alcohol injection, continue today with thermal ablation methods such as radiofrequency ablation (RFA), microwave ablation (MWA), cryoablation (CA), and the non-thermal ablation method, which is irreversible electroporation (9-11). The current literature reports that the local ablative treatments showed similar oncological outcomes when compared to the surgical treatment methods. However, local ablative treatment methods had lower complication rates and superior outcomes in renal function protection (12-15). Shorter recovery times and hospital stays, being minimally invasive procedures, having a minimal risk on ischemic injury, and their nephron-sparing features, are some of the advantages of the local treatment options over surgery. Due to these described features and advantages, local ablative treatment choices offer curative nephron-sparing treatment in SRM, especially for the patients having comorbidities that make surgery impossible (16-20).

There are several articles regarding RFA and CA in the treatment of SRM under the guidance of cross-sectional imaging such as computed tomography (CT) and magnetic resonance (MR) imaging in the current literature. Nevertheless, there are limited data regarding the MWA of SRMs under ultrasound (US)-guidance (11). This present study aimed to evaluate the short- and mid-term results and outcomes, efficacy, safety, and possible prognostic contributions of US-guided percutaneous MWA treatment performed on SRM.

\section{METHODS}

This retrospective study was approved by the local ethics committee (Prof. Dr. Cemil Taşcıoğlu State Hospital, 48670771514.10). Informed consent was obtained from all the patients. The authors confirm that the study was carried out in accordance with the Declarations of Helsinki.

\section{Patient Selection}

We retrospectively analyzed the patients who had undergone US-guided percutaneous MWA of SRM using both their patient files that contained all of the follow-up informations and all the radiological images on the local picture archiving and communication system between July 2016 and July 2019. All the patients were asymptomatic individuals with the coincidental detection of a SRM that was compatible with a T1 tumor according to their CT or MR images. T1 tumor was accepted as a tumor that was $7 \mathrm{~cm}$ across or smaller and was only present in the kidney with no spread to lymph nodes or distant organs.
All the patients were technically appropriate for percutaneous MWA.

\section{Microwave Ablation Procedure}

All MWA procedures were performed percutaneously by a radiologist who was experienced in interventional radiology and performed more than 15 percutaneous thermal ablation treatment with using only US guidance under deep sedation. MWA systems were 15-gauge electrodes with $2.45 \mathrm{GHz}$ Solero and Acculis MWA generators (Angiodynamics, New York, USA) in all the procedures. Aplio 500 US system (Toshiba Medical Systems Corporation, Tochigi, Japan) had been used with 3-6 Mhz convex or 4-9.2 Mhz linear array transducers for the ablation guidance. All the patients whose preparations were made before the procedure were positioned on a sterile table in prone, lateral decubitus, or modified decubitus positions in accordance with the procedure plan. Following the local anesthetic infiltration throughout the ablation tract, the MWA probe was advanced towards the center of the lesion. Once the active part of the ablation probe was positioned at the center of the targeted ablation zone, two interventional radiologists checked whether the lesion had been centralized or not from different planes using US probe maneuvers. After ensuring the correct position, the ablation was started with deep sedation. The ablation time and energy level were selected from the guide determined by the manufacturer and adjusted to fit the lesion size properly, including the safety zone which was at least $5 \mathrm{~mm}$ for each margin around the tumor. Midazolam hydrochloride (3-5 mg) and fentanyl citrate (100-300 $\mu \mathrm{g}$ ) were administered intravenously for the deep sedation. Immediately after adequate sedation, the ablation process was begun. The ablation process was controlled by following the bubbles, indicating the ablation and spread throughout the ablation zone around the probe with dynamic USG imaging (Figure 1). When considering incomplete ablations like in the case of large tumors or tumors in challenging locations etc., it was tried to cover the all lesion by repositioning the ablation probe.

\section{Patient Follow-up and Definitions}

Immediately after the ablation process, all the patients were referred to their clinic's inpatient service to monitor their vital signs, blood parameters, and renal function tests during the post-procedural first day. Control CT or MR imaging with US were obtained for each patients to evaluate the presence early complications and major residual tumor at the end of the first day after the ablation. The cross-sectional imaging was performed with intravenous contrast material administration 
depending on the kidney functions of the patients. Then, all the patients underwent contrast enhanced (CE) CT scans or dynamic CE MR imaging were performed quarterly in the first 2 years, and biannually thereafter for follow-up (Figure 2). Besides, diffusion-weighted (DW) MR imaging obtained at different $b$ values and apparent diffusion coefficient maps created from these data were added to the MR controls. In the first month control, the area with contrast enhancement on CE CT or MR images and/or the diffusion restriction on DW MR images were considered as the presence of a residual tumor due to incomplete ablation. Otherwise, the ablation was accepted as complete and successful. Local recurrence was defined as the ablated area with new contrast enhancement and/or the diffusion restriction on DW MR images in any of the follow-up period longer than three months (Figure 3). Patients with the incomplete ablation and local recurrence underwent a new MWA session.

\section{Data Obtaining}

Age and gender of the patients were recorded. The following data and parameters were also obtained: histopathologic type of the SRM, pre and postablative tumor size in three dimensions (width, length, and height), tumor localization, the ablation procedure data (patient position, time, energy, presence of repeated ablation, adjacent structures, usage of protective techniques such as hydrodissection), time of local recurrence, and renal function test and parameters [urea, creatinine, and glomerular filtration rate (GFR)]. According to the growth pattern and tumor localizations, the lesions were classified into four groups (Figure 4). In CT images of the day after the procedure, the subcutaneous tissue thickness from the anterior part of linea alba at the L3 vertebral body level was measured and grouped in $0.5 \mathrm{~cm}$ intervals to evaluate the effect of body mass by means of fatty tissue. To evaluate the impact of the interventional radiologist's experience, the MWA procedures were grouped into year ranges based on the first renal microwave procedure in 2016.

\section{Statistical Analysis}

Continous and categorical variables were presented as median (IQR) and number (\%). Mann-Whitney $\mathrm{U}$ test, chi-square test, or Fisher extact test were used to compare the differences between the groups. An overall p value of less than 0.05 was as a statisfically significant result. Statistical analysis was performed with Statistical Package of the Social Sciences (SPSS) version 22.0 (IBM Corp.).

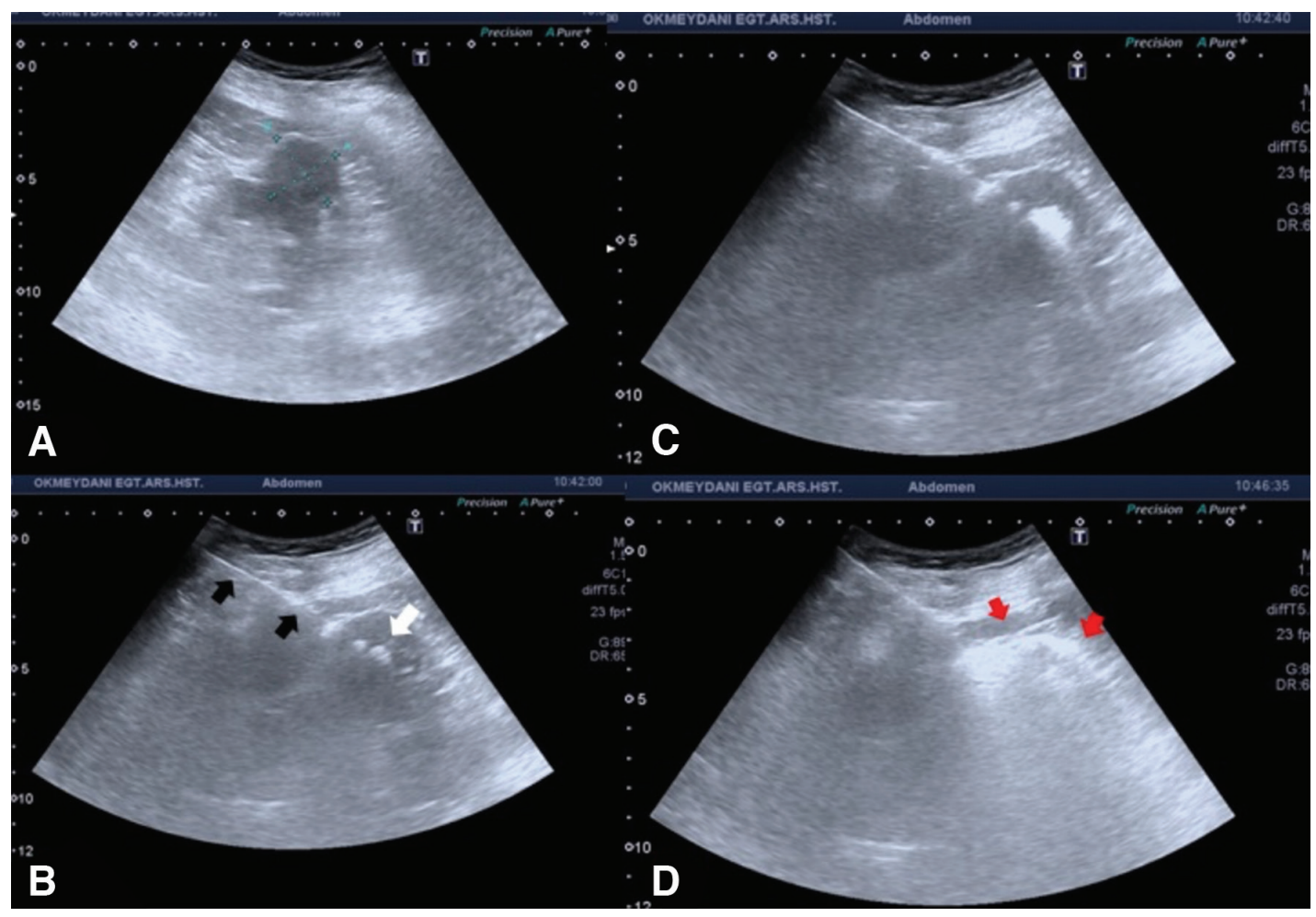

Figure 1. Ultrasound-guided microwave ablation procedure of a small renal mass. The lesion localization is in the middle part of the kidney with the exophytic morphology (A). Ablation probe's (black arrows in B) active part is positioned at the center of the targeted ablation zone and after ensuring the correct position, the ablation is begun with the bubbles (white arrow in B) which indicate the ablation process (B, C). Covering the all lesion with bubbles (red arrows in D) at the end of the targeted ablation time 


\section{RESULTS}

\section{Patient Population and Lesion Classifications}

Thirteen patients with thirteen solitary SRMs that were ablated using MWA under US-guidance were found. Of these patients, seven patients were females and six were males. The mean age of the patients was 75.38 (range; $48-86$ years) (IQR: 7280). The histopathologic types of the tumors were detailed in Figure 5. Twelve patients had inappropriate conditions for surgical treatment due to a high risk of undergoing surgery and anesthesia, poor and limited renal function, and clinically important comorbidities. One patient having a history of
Von Hippel-Lindau Syndrome underwent a previous partial neprectomy surgery on the contralateral kidney.

The mean longest diameter of the lesions was $33.53 \mathrm{~mm}$ (range; 28-50 mm) (Figure 6). Of the thirteen lesions, four lesions (31\%) were in the exophytic, four lesions in the parenchymal (31\%), and five lesions (38\%) in the exophytic parenchymal location (Figure 4, Figure 7). Distribution of the lesions according to the longest diameter, the categorization of the subcutaneous tissue thickness, and the distribution of the lesions related to the interventional radiologist's years of experience are summarized in Table 1-3, respectively.

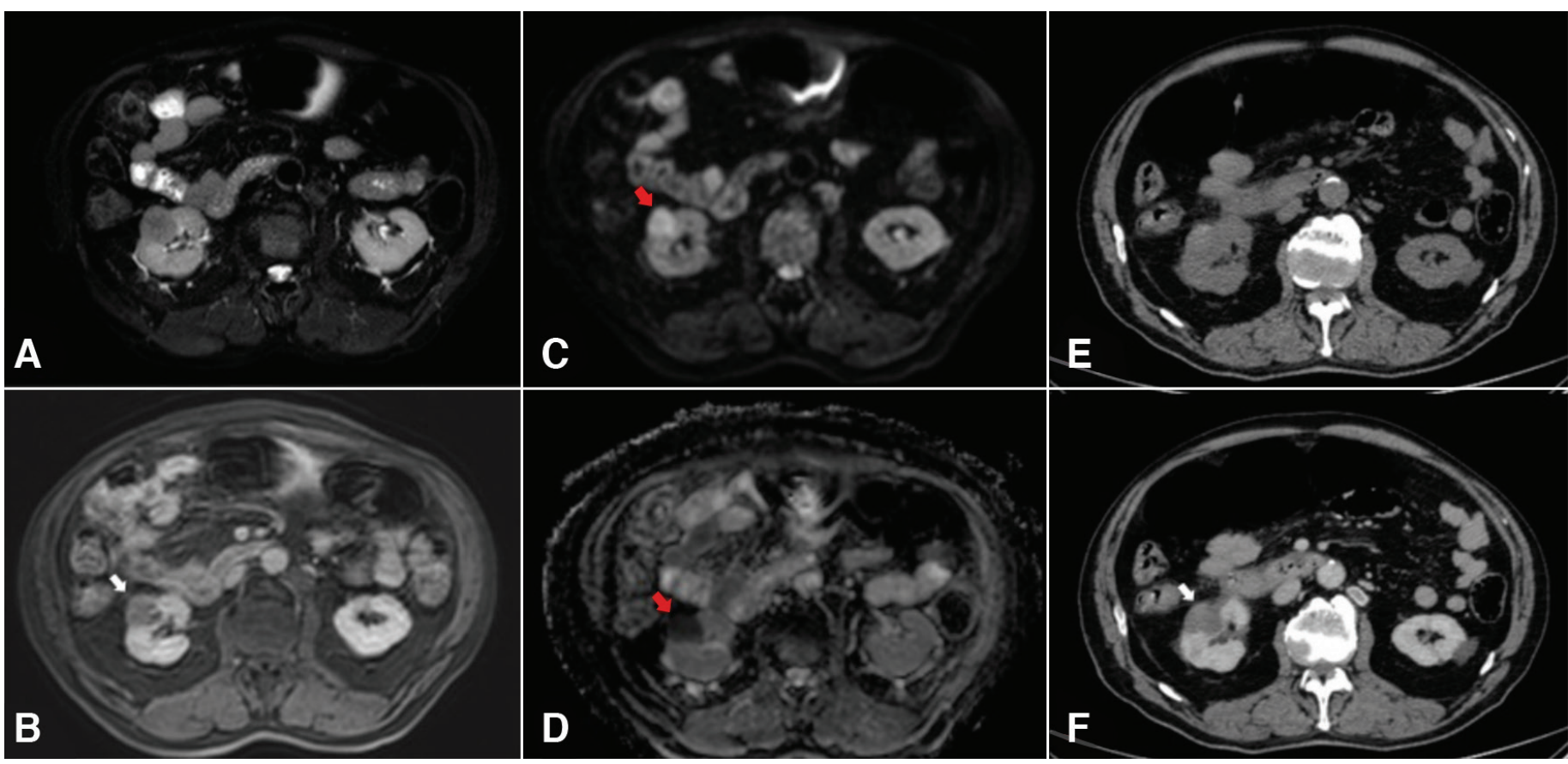

Figure 2. Contrast enhanced (CE) magnetic resonance (MR) images before the procedure (A-D) and follow-up CE computed tomography (CT) images (E, F). Well-demarcated SRM that was showing peripheral contrast enhancement and exophytic parenchymal localization in the right kidney (white arrow in B). The lesion showed diffusion restriction in diffusion weighted MR images (red arrows in C and D). In her first month follow-up, CE CT images demonstrated the ablation zone with no evidence of a residual tumor, compatible the complete ablation (white arrow in F) SRM: Small renal masses

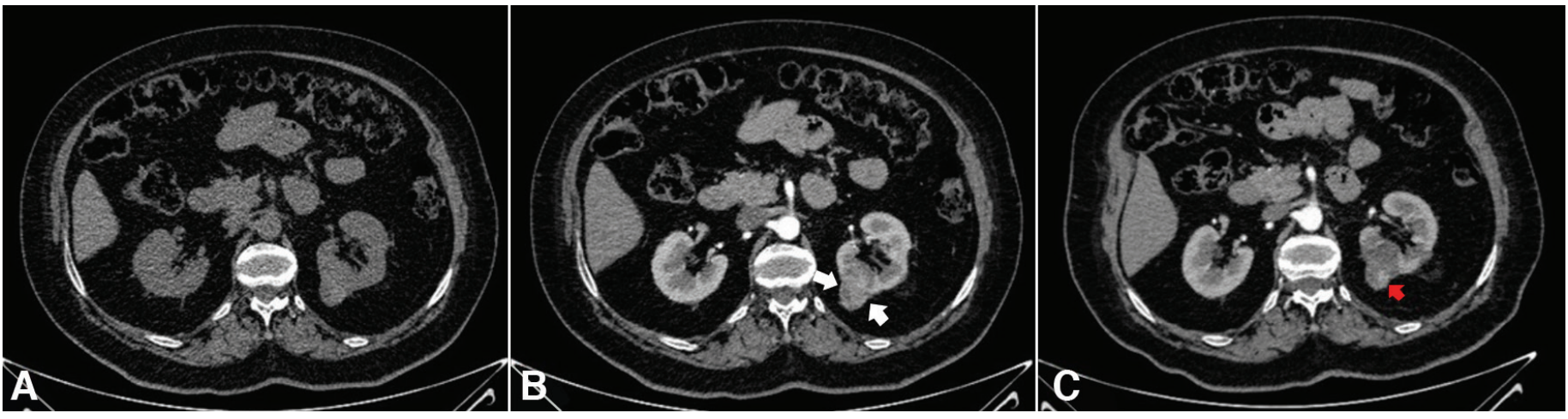

Figure 3. Dynamic contrast enhanced (CE) computed tomography (CT) images of a 69-year- old female patient with a small renal mass in the left kidney. Axial CT images before (A) and after (B) intravenous contrast administration show the exophytic parenchymal mass lesion (white arrows in B). In her first month follow-up CE CT, nodular residual lesion (red arrow) was demonstrated in the posterior part of the ablation zone (C) 


\section{Microwave Ablation Procedure}

Among the thirteen patients with the thirteen SRM, we performed one session for six lesions (46\%), two sessions for six lesions (46\%), and three sessions for one lesion (8\%). Thus, twenty-one ablation sessions were performed in thirteen SRMs. The mean energy level applied to the lesion during the ablation period was 109 watts (range; 80-140) per session. Since there was no finding to

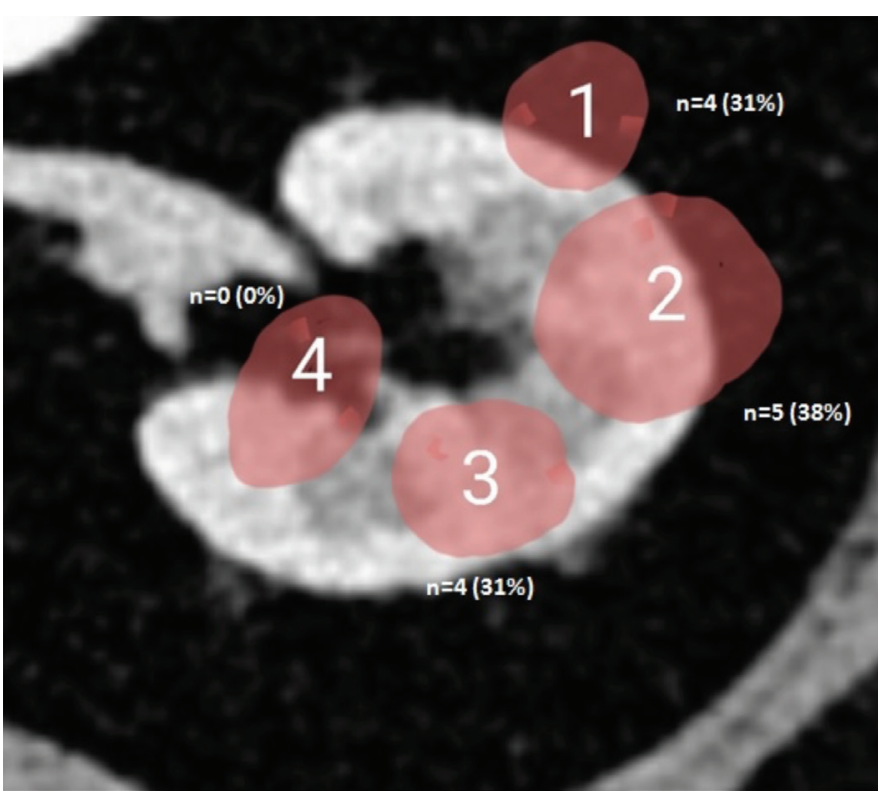

Figure 4. Classification of the tumor localizations according to growth patterns. Exophytic (1), exophytic parenchymal (2), parenchymal (3) and endophytic (4) patterns of the localization

\section{Histopathologic Types}

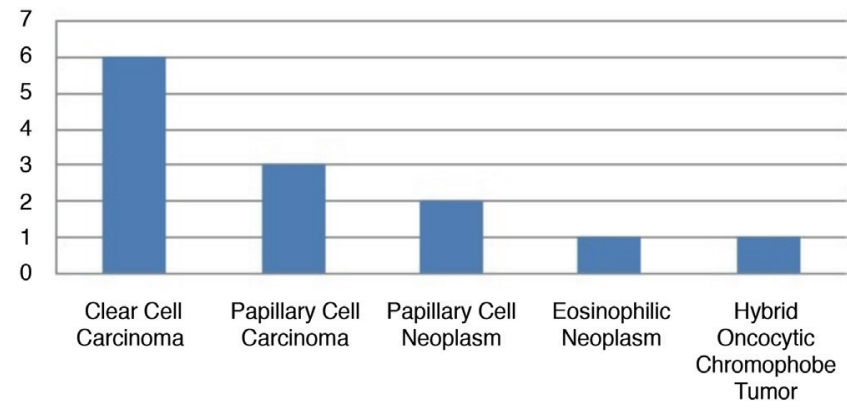

Figure 5. The histopathologic types of the ablated small renal masses

Table 1. Relationship between the longest diameter of the small renal mass and the presence of a residual lesion

\begin{tabular}{|c|c|c|c|c|}
\hline \multirow{2}{*}{ Longest Diameter $(\mathrm{cm})$} & \multicolumn{2}{|c|}{ Residual lesion } & \multirow{2}{*}{ Total } & \multirow[t]{2}{*}{$p$ value } \\
\hline & No & Yes & & \\
\hline $2-3$ & 4 & 0 & 4 & \multirow{4}{*}{0.590} \\
\hline $3-4$ & 6 & 2 & 8 & \\
\hline $4-5$ & 1 & 0 & 1 & \\
\hline Total & 11 & 2 & 13 & \\
\hline
\end{tabular}

terminate the ablation in any patient, ablation procedures were continued till the specified target times were reached in all the patients. Mean ablation time was 2.54 minutes (range; 1.5-4) for each session. We demonstrated a complete ablation in eleven patients (84\%) in first month control CT imaging as a primary success. In this first follow-up $\mathrm{CT}$, since two residual tumors were detected in two patients (16\%), new ablation sessions were planned to achieve the complete ablation. After the completion of ablations with mean ablation time of 2.5 minutes and mean energy level of 90 watts, secondary success was obtained as $100 \%$. since there was no endophytic lesion or the lesion with adjacent organ proximity less than $5 \mathrm{~mm}$, asisted tecniques such as cold pyeloperfusion and hydrodissection that are used to prevent the pelvicalyceal system or adjacent structures from the non-target ablation were not performed in any procedure. Two (16\%) lesions with residual tumor after the first ablation session were located in the exophytic parenchymal site (Table 4). The features of the lesions with residual tumors are presented in Table 5 . Technical success rates were $83 \%(n=5 / 6), 83 \%(n=5 / 6)$, and $100 \%(n=1 / 1)$ for one ablation, two ablations, and three ablations in a single session, respectively.

\section{Patient Follow-up}

The mean follow-up period after the successful procedures was 26 months (range; 5-46). One patient died due to myocardial infarction in the 5th month of follow-up regardless of the

Table 2. Relationship between the years of experience of the interventional radiologist and the presence of a residual lesion

\begin{tabular}{|l|c|c|c|c|}
\hline \multirow{2}{*}{ Years of Experience } & \multicolumn{2}{|c|}{$\begin{array}{c}\text { Residual } \\
\text { lesion }\end{array}$} & \multirow{2}{*}{ Total } & \multirow{2}{*}{$p$ value } \\
\cline { 2 - 4 } & No & Yes & & \\
\hline $0-1$ & 2 & 0 & 2 & \multirow{2}{*}{0.244} \\
\cline { 1 - 4 }-2 & 4 & 0 & 4 & \multirow{2}{*}{} \\
\hline $2-3$ & 5 & 1 & 6 & \\
\hline $3-4$ & 0 & 1 & 1 & \\
\hline Total & 11 & 2 & 13 & \\
\hline
\end{tabular}

Table 3. Relationship between the subcutaneous tissue thickness and the presence of a residual lesion

\begin{tabular}{|l|c|c|c|c|}
\hline \multirow{2}{*}{$\begin{array}{l}\text { Subcutaneous tissue } \\
\text { thickness }(\mathrm{cm})\end{array}$} & \multicolumn{2}{|c|}{ Residual lesion } & \multirow{2}{*}{ Total } & \multirow{2}{*}{$\mathbf{p}$ value } \\
\cline { 2 - 4 } & No & Yes & & \\
\hline $1-1.5$ & 2 & 0 & 2 & \multirow{2}{*}{} \\
\hline $1.5-2$ & 4 & 1 & 5 & \multirow{2}{*}{1.0} \\
\hline $2-2.5$ & 2 & 0 & 2 & \\
\hline $2.5-3$ & 2 & 0 & 2 & \\
\hline $3-3.5$ & 1 & 1 & 2 & \\
\hline Total & 11 & 2 & 13 & \\
\hline
\end{tabular}


procedure and renal mass. When this patient was excluded, the mean follow-up period was revised as 27.8 months (range; 11-46). The follow-up periods were less than one year, between 1-2 years, between 2-3 years, and between 3-4 years in one patient (8\%), three patients (23\%), six patients (46\%), and three patients (23\%), respectively. General technical effectiveness and local tumor control rates were $100 \%$ with eleven lesions that were completely ablated in a single session, and two lesions with residual tumors that were completely ablated after a second session of ablation. Cancer-specific survival rate was $100 \%$. One-year, two-years, and three-years of general survival and the disease-free survival rates were 100\%, 100\%, 92\% and

\section{Longest Diameter}

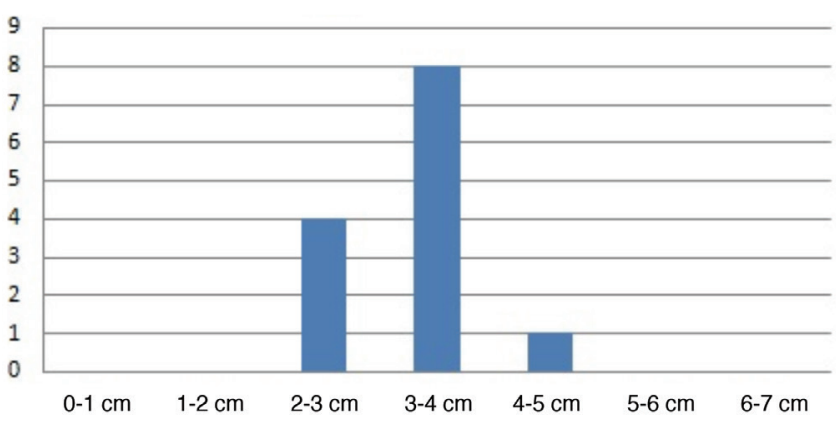

Figure 6. Distribution of the tumors according to longest diameter of the lesion

\section{Side and Localization}

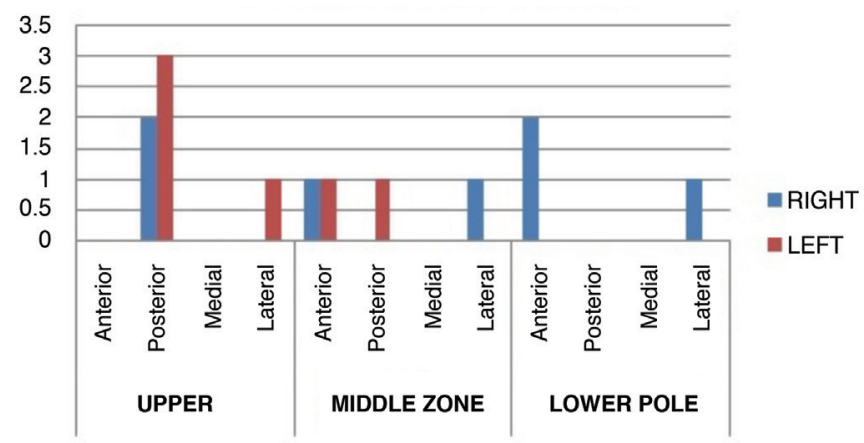

Figure 7. Distribution of the tumors according to the site and localization

Table 4. Relationship between the localization of the small renal mass and the presence of a residual lesion

\begin{tabular}{|l|c|c|c|c|}
\hline \multirow{2}{*}{ Localization } & \multicolumn{2}{|c|}{ Residual lesion } & \multirow{2}{*}{ Total } & \multirow{2}{*}{ p value } \\
\cline { 2 - 3 } & No & Yes & & \\
\hline Exophytic & 2 & 0 & 2 & \multirow{2}{*}{0.154} \\
\hline Parenchymal & 4 & 0 & 4 & \multirow{2}{*}{7} \\
\cline { 1 - 3 } Exophytic parenchymal & 5 & 2 & 13 & \\
\hline Total & 11 & 2 & \\
\hline
\end{tabular}

100\%, 100\%, 100\% respectively. There was no evidence of distant metastasis in any patients.

\section{Complications}

Only one patient developed a perinephric hematoma controlled by intravenous hemostatic therapy. After the hematoma was complicated with abscess formation, the patient was successfully treated by percutaneous drainage catheter placement under USguidance and antibiotherapy. Apart from that, no major and minor complications occurred in any patient.

\section{Renal Functions}

Mean serum creatinine level was $1.07 \mathrm{mg} / \mathrm{dL}$ (range; 0.55-1.95) before the MWA procedure and $1.13 \mathrm{mg} / \mathrm{dL}$ (range; 0.6-2.36) one week after procedure. Mean estimated GFR (eGFR) level was $64 \mathrm{~mL} / \mathrm{min} / \mathrm{m}^{3}$ (range; 28-111) before the MWA procedure and $64.7 \mathrm{~mL} / \mathrm{min} / \mathrm{m}^{3}$ (range; 21-109) one week after procedure. In the follow-up examinations, a $20 \%$ increase was observed in the two patients' creatinine values, and these two patients were observed to be the ones with the highest creatinine values and the lowest eGFR values before the procedure. Including these two patients, no dialysis was required in any patient after the procedure.

\section{DISCUSSION}

Despite the well accepted surgical results and outcomes of partial nephrectomy, advances in imaging techniques and medical technology have brought the increasingly frequent use of thermal ablative treatments as an alternative curative method to surgical tumor excision, which is more conservative and minimally invasive in the treatment of SRM (20). Additionally, some advantages of these treatment methods such as having less complication rates than surgical treatments, shorter recovery times and hospital stay, not causing ischemic damage to the kidney, and most importantly, offering curative and nephron-sparing treatments to patients who are not suitable for the surgical treatments, increased their use in routine practice (16-20).

It is stated in the urooncology guidelines that RFA and CA, which are the widely used thermal ablation methods, could be taken into consideration in the treatment of T1a renal masses. Although there are fewer studies about MWA in the treatment of SRM compared to RFA and CA, the technical success and safety of MWA has been defined (11). In our study, we demonstrated the efficacy of US-guided MWA with the results and follow-up data of thirteen patients who underwent SRM treatment using MWA. We defined the general and the secondary success rates as $100 \%$ and this result was found to be comparable to the results 


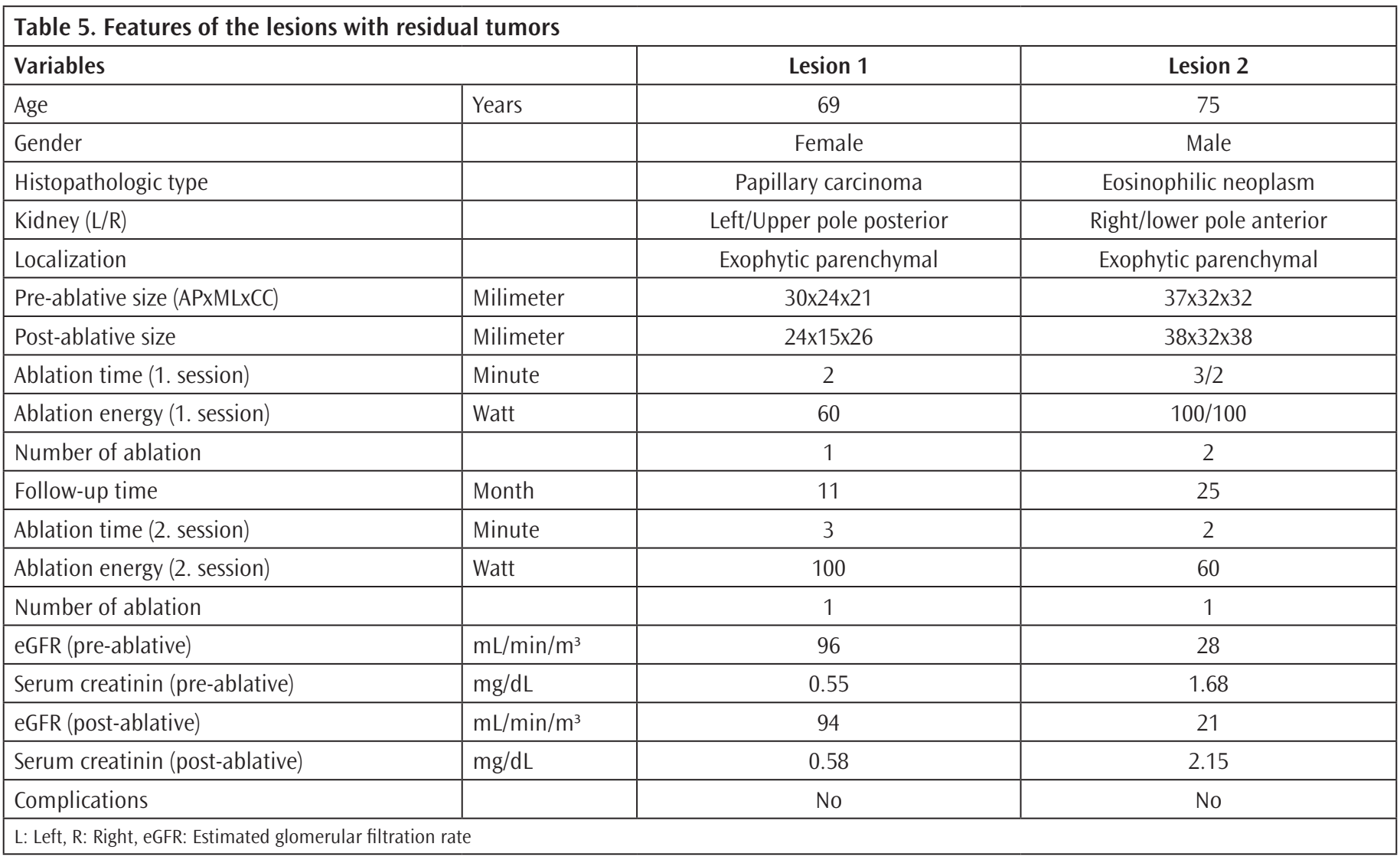

reported in the literature $(11,21-26)$. Although local recurrence after MWA treatment is a disadvantage compared to partial nephrectomy, the high success rate achieved by courtesy of its easy repeatability both during the procedure and during the follow-up is an important advantage $(9,11)$.

Factors that may affect the results of MWA can be listed as follows: tumor size, tumor localization, ablation time, applied energy level, the surface area of the ablation prob's active tip, tissue resistance (27). Tumor size is a determining factor in the patient selection and prediction of the procedural success in MWA. While the complete ablation rate is reported to be approximately $85 \%$ in renal masses of $3 \mathrm{~cm}$ and smaller, this rate decreases as tumor size increases and the need for complementary MWA is reported to increase $(11,16-23)$. Another important factor affecting the success of the procedure is the tumor localization. It is known that the complete ablation rate is higher in the first session in tumors that are far from the renal pedicle and collecting system, located in the posterior and exophytic site, in other words, non-vascular perinephritic tissue (16-20). In contrast with the literature data, two (16\%) lesions with residual tumor after the first ablation session were located as exophytic parenchymal in our study. It was observed that histopathologic type, tumor localization, growth pattern, tumor size, total energy level during ablation process, interventional radiologist's experience, subcutaneous tissue thickness, and number of ablation in the first sessions did not show a statistically significant relatioship in terms of residual tumors in the present study.

Thermal ablation processes can be performed under the imaging guidance of US, CT, or MR. The selection of ablation method depends on the interventional radiologist's preference and expertise and the clinic's ability to access imaging facilities $(11,12)$. Combined methods with CT or MR can also be used in real-time fusion imaging to guide and to monitor the tumor ablation procedures. The most important advantages of US is that it allows the insertion of ablation probes in real time and does not contain ionizing radiation. However, its high operator dependency, gas artifacts due to adjacent intestinal structures, and application difficulties in obese patients are known disadvantages of the US (11). In addition, it is not always possible to differentiate the parenchymal component of the tumor from the normal parenchyma in US-guidance (28-30). CT has some advantages over US, including its less operator dependency, no intestinal gas artifact, and clear view of the 
adjacent structures in multiplanar reconstructed images (11) To the best of our knowledge, there was no literature data that compared US and cross-sectional imaging guidance. Due tot technical reasons related to anesthesia support in the CT unit, we performed the thermal ablation treatments of SRM under US guidance in our department. Although our general success rate is similar to data in the current literature, we think that the technical failure of the two residual tumors in our study was due to the feature of the US, which is the limitation in the differentiation of the tumor border and adjacent renal parenchyma since these lesions were in an exophytic parenchymal localization. Our claim is supported by the data that the exophytic parenchymal localization of lesions with residual tumors rather than the endophytic localization that was accepted as more likely in terms of residue and the time of the ablation processes were in the partially experienced years of the interventional radiologist. It is clear that there is a need for randomized controlled trials comparing CT, MR, and combined methods with US.

In retrospective cohort studies, MWA had early and mid-term results comparable to RFA and CA, and the 3- and 5-year diseasefree survival rates were reported $93 \%$ and $88 \%$, respectively (21,24-26,31-33). It is mentioned in a meta-analysis about the effectiveness of thermal ablative treatment methods that there was no difference between MWA and CA in terms of local or metastatic recurrence despite the larger tumor size in MWA than CA (33). Yu et al. (24) reported that the recurrence rate was 0-23\% in the follow-up of tumors that have been successfully ablated at the first session. In our study, no evidence of local tumor recurrence or distant metastasis (0\%) were found in an average follow-up period of 26 months congruently with literature data.

It was revealed that MWA was superior to other local ablative methods in T1b renal tumor treatment. When compared to RFA, shorter ablation times, lesser heat sink effect, and the ability to achieve larger ablation zones can be considered as the advantages of MWA. Also, Ahmad et al. (34) mentioned that MWA showed better results in reducing kidney damage and in tolerability compared to RFA and CA.

MWA is a minimal invasive treatment choice compared to surgery. However, there could be some minor and major complications after MWA as follows; perirenal hematoma, macroscopic hematuria, bleeding, infection, stenosis or fistula formation due to non-target ablation of pelvicaliceal system, adjacent organ damage, and the pain at the site of ablation $(35,36)$. In these current series, complication rates were reported as $4.8 \%$, which was less than half of the rates reported for partial nephrectomy (11\%) (21). In our study, self-limiting perirenal hematoma that did not require transfusion was observed in one (7.6\%) case and it was a little bit higher than the literature data.

The recent studies have shown that ablative treatment methods are superior to surgery in the protection of the kidney function $(11,12,27)$. We demonstrated that there was no significant difference between pre- and post-ablative serum creatinine and eGFR values in the present study.

We had several limitations in our study. The first and main limitation was the small sample size. Because of this, we could not conduct the subgroup analyses and the comparisons including the size, histopathologic types, and the localization. Larger sample size with subgroup analysis including different localizations and tumor sizes are needed in future studies. The second is the retrospective design and the short follow-up time of the study. Randomized controlled prospective studies with longer follow-up times are required. Despite these, the limited experience of MWA treatment of SRM through the literature and usage of US-guidance are the superior features of our study.

\section{CONCLUSION}

MWA in the treatment of SRM is an effective and safe method due to its high technical success and low complication rates, its renal function sparing features and good short- and mid-term results and outcomes when compared to RFA and CA.

\section{Ethics}

Ethics Committee Approval: Retrospective study was approved by the local ethics committee (Prof. Dr. Cemil Tașcıoğlu State Hospital, 48670771-514.10).

Informed Consent: Informed consent was obtained from all the patients.

Peer-review: Externally peer-reviewed.

\section{Authorship Contributions}

Surgical and Medical Practices: S.A., Concept: E.K., Design: S.A., E.K., Data Collection or Processing: S.A., E.K., Analysis or Interpretation: E.K., Literature Search: E.K., Writing: S.A.

Conflict of Interest: No conflict of interest was declared by the authors.

Financial Disclosure: The authors declared that this study received no financial support. 


\section{REFERENCES}

1. Sanchez A, Feldman AS, Hakimi AA. Current Management of Small Renal Masses, Including Patient Selection, Renal Tumor Biopsy, Active Surveillance, and Thermal Ablation. J Clin Oncol 2018;36:3591-600.

2. Lucas SM, Stern JM, Adibi M, Zeltser IS, Cadeddu JA, Raj GV. Renal function outcomes in patients treated for renal masses smaller than 4 cm by ablative and extirpative techniques. J Urol 2008;179:75-80 .

3. Huang WC, Levey AS, Serio AM, Synder M, Vickers AJ, Raj GV, et al. Chronic kidney disease after nephrectomy in patients with renal cortical tumours: a retrospective cohort study. Lancet Oncol 2006;7:735-40.

4. Herr HW. Partial nephrectomy for unilateral renal carcinoma and a normal contralateral kidney: 10-year followup. J Urol 1999;161:33-4.

5. Fergany AF, Hafez KS, Novick AC. Long-term results of nephron sparing surgery for localized renal cell carcinoma: 10-year followup. J Urol 2000;163:442-5.

6. Gill IS, Kavoussi LR, Lane BR, Blute ML, Babineau D, Colombo Jr. JR, et al. Comparison of 1,800 laparoscopic and open partial nephrectomies for single renal tumors. J Urol 2007;178:41-6.

7. Park H, Byun SS, Kim HH, Lee SB, Kwon TG, Jeon SH et al. Comparison of laparoscopic and open partial nephrectomies in t1a renal cell carcinoma: a Korean multicenter experience. Korean J Urol 2010;51:467-71.

8. Campbell SC, Novick AC, Belldegrun A, Blute ML, Chow GK, Derweesh IH, et al. Guideline for management of the clinical T1 renal mass. J Urol 2009;182:1271-9.

9. Ansari D, Andersson R. Radiofrequency ablation or percutaneous ethanol injection for the treatment of liver tumors. World J Gastroenterol 2012;18:1003-8.

10. Knavel EM, Brace CL. Tumor ablation: common modalities and general practices. Tech Vasc Interv Radiol 2013;16:192-200.

11. Zhong J, Wah TM. Renal ablation: current management strategies and controversies. Chin Clin Oncol 2019;8:63.

12. Venkatesan AM, Wood BJ, Gervais DA. Percutaneous Ablation in Kidney. Radiology 2011;261:375-91.

13. Sun M, Abdollah F, Bianchi M, Trinh QD, Jeldres C, Thuret R, et al Treatment management of small renal masses in the 21st century: A paradigm shift. Ann Surg Oncol 2012;19:2380-7.

14. Rivero JR, De La Cerda J 3rd, Wang H, Liss MA, Farrell AM, Rodriguez R, et al. Partial Nephrectomy versus Thermal Ablation for Clinical Stage T1 Renal Masses: Systematic Review and Meta-Analysis of More than 3,900 Patients. J Vasc Interv Radiol 2018;29:18-29.

15. Pierorazio PM, Johnson MH, Patel HD, Sozio SM, Sharma R, Iyoha E, et al. Management of Renal Masses and Localized Renal Cancer: Systematic Review and Meta-Analysis. J Urol 2016;196:989-99.

16. Gervais DA, McGovern FJ, Arellano RS, McDougal WS, Mueller PR. Radiofrequency ablation of renal cell carcinoma: part 1, Indications, results, and role in patient management over a 6-year period and ablation of 100 tumors. AJR Am J Roentgenol 2005;185:64-71.

17. Park SH, Yoon SK, Cho JH, Oh JY, Nam KJ, Kwon HJ, et al. Radiofrequency ablation treatment for renal cell carcinoma: early clinical experience. Korean J Radiol 2008;9:340-7.

18. Zlotta AR, Wildschutz T, Raviv G, Peny MO, Gansbeke DV, Noel JC, et al. Radiofrequency interstitial tumor ablation (RITA) is a possible new modality for treatment of renal cancer: ex vivo and in vivo experience. Endourol 1997;11:251-8.
19. Matsumoto ED, Johnson DB, Ogan K, Trimmer C, Sagalowsky A, Margulis $V$, et al. Shortterm efficacy of temperature-based radiofrequency ablation of small renal tumors. Urology 2005;65:877-81.

20. Wingo MS, Leveillee RJ. Central and deep renal tumors can be effectively ablated: radiofrequency ablation outcomes with fiberoptic peripheral temperature monitoring. J Endourol 2008;22:1261-7.

21. Chan P, Vélasco S, Vesselle G, Boucebci S, Herpe G, Debaene B, et al. Percutaneous microwave ablation of renal cancers under CT guidance: safety and efficacy with a 2-year follow-up. Clin Radiol 2017;72:786-92.

22. Choi SH, Kim JW, Kim JH, Kim KW. Efficacy and Safety of Microwave Ablation for Malignant Renal Tumors: An Updated Systematic Review and MetaAnalysis of the Literature Since 2012. Korean J Radiol 2018;19:938-49.

23. Wells SA, Wheeler KM, Mithqal A, Patel MS, Brace CL, Schenkman NS Percutaneous microwave ablation of $\mathrm{T} 1 \mathrm{a}$ and $\mathrm{T} 1 \mathrm{~b}$ renal cell carcinoma: short-term efficacy and complications with emphasis on tumor complexity and single session treatment. Abdom Radiol 2016;41:1203-11.

24. Yu J, Liang P, Yu XL, Cheng ZG, Han ZY, Mu MJ, et al. US-guided percutaneous microwaveablation of renal cell carcinoma: intermediateterm results. Radiology 2012;263:900-8.

25. Yu J, Zhang G, Liang P, Yu XL, Cheng ZG, Han ZY, et al. Midterm results of percutaneous microwave ablation under ultrasound guidance versus retroperitoneal laparoscopic radial nephrectomy for small renal cell carcinoma. Abdom Imaging 2015;40:3248-56.

26. Ierardi AM, Puliti A, Angileri SA, Petrillo M, Duka E, Floridi C, et al, Microwave ablation of malignant renal tumours: intermediate-term results and usefulness of RENAL and mRENAL scores for predicting outcomes and complications. Med Oncol 2017;34:97.

27. Yüksel MB, Gümüs B, Özbek E, Karaköse A, Tarhan S, Temeltas G, et al. Minimally Invasive Treatment in Kidney Tumors: Initial Experience in Radiofrequency- Ablation. Kocatepe Medical Journal 2014;15:116-23.

28. Maybody M. An overview of image-guided percutaneous ablation of renal tumors. Semin Intervent Radiol 2010;27:261-7.

29. Ng CS, Wood CG, Silverman PM, Tannir NM, Tamboli P, Sandler CM. Renal cell carcinoma: diagnosis, staging and surveillance. AJR Am J Roentgenol 2008;191:1220-32.

30. van Oostenbrugge TJ, Fütterer JJ, Mulders PFA. Diagnostic Imaging for Solid Renal Tumors: A Pictorial Review. Kidney Cancer 2018;2:79-93.

31. Klapperich ME, Abel EJ, Ziemlewicz TJ, Best S, Lubner MG, Nakada SY, et al. Effect of Tumor Complexity and Technique on Efficacy and Complications after Percutaneous Microwave Ablation of Stage T1a Renal Cell Carcinoma: A Single-Center, Retrospective Study. Radiology 2017;284:272-80.

32. Li X, Liang P, Yu J, Yu XL, Liu FY, Cheng ZG, et al. Role of contrastenhanced ultrasound in evaluating the efficiency of ultrasound guided percutaneous microwave ablation in patients with renal cell carcinoma. Radiol Oncol 2013;47:398-404.

33. Martin J, Athreya S. Meta-analysis of cryoablation versus microwave ablation for small renal masses: is there a difference in outcome. Diagn Interv Radiol 2013;19:501-7.

34. Ahmad F, Gravante G, Bhardwaj N, Strickland A, Basit R, West K, et al. Renal effects of microwave ablation compared with radiofrequency, cryotherapy and surgical resection at different volumes of the liver treated. Liver Int 2010;30:1305-14.

35. Aron M, Gill IS. Renal tumor ablation. Curr Opin Urol 2005;15:298-305.

36. Kwan KG, Matsumoto ED. Radiofrequency ablation and cryoablation of renal tumours. Curr Oncol 2007;14:34-8. 